\title{
ФАКТОРЫ, ПРОВОЦИРУЮЩИЕ НАРУШЕНИЕ ГЛИКЕМИЧЕСКОГО КОНТРОЛЯ
}

\author{
Южакова А.Е., Нелаева А.А., Хасанова Ю.В., Нефедова А.Б. \\ ГАУЗ ТО «Многопрофильный консультативно-диагностический центр», г. Тюмень \\ ФГБОУ ВО «Тюменский государственный медицинский университет» Минздрава России, г. Тюмень
}

ЦЕЛЬ: рассмотреть факторы провоцирующие нарушение гликемического контроля.

МАТЕРИАЛЫ И МЕТОДЫ: Нами был проведен анализ дневников питания, теста Хорна-Остберга, гликемии натощак, базальной температуры (БТ, как маркера уровня мелатонина) в установленное время $(8.00,11.00,14.00,17.00,19.00,23.00,03.00$ ч.) среди пациентов с РНУО, СД2 со стажем заболевания до 5 лет и без нарушений углеводного обмена.

РЕЗУЛЬТАТЫ И ОБСУЖДЕНИЕ: ПациентЫ 3 грУпП бЫли сопоставимы по возрасту и полу (40-69 лет,

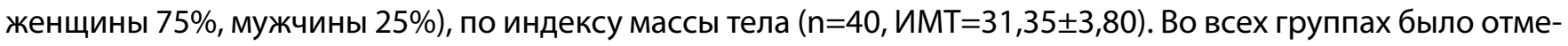
чено смещение количества употребляемых калорий на вторую половину дня, так в группе контроля коли-

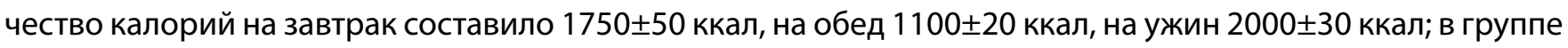

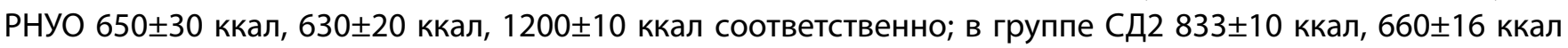
и $330 \pm 10$ ккал соответственно. По распределению белков, жиров и углеводов в рационе контрольной группы соотношение составило 1:1,5:4,5, в группе с РНУО 1,2:1:3,3, в группе с СД2 1,9:1:4,3. Так, во всех группах преобладало количество углеводов (в основном мучные изделия и фруктоза), с тенденцией увеличения роста потребляемого белка. В рационе больных РНУО и СД2 отсутствовали полиненасыщенные жирные кислоты, количество клетчатки было минимальным. Прием пищи был 5-6разовым, с интервалами не более 2-3 ч. Была тенденция к более позднему завтраку (9.3-10.00 ч) и ужину (19-20.00 ч). Продолжительность сна в группах в среднем составила 6 1 часов в сутки, отход ко сну осуществлялся в интервале 22-23.30 ч. Уровень БТ в группе РНУО был значительно выше (в 3.00 ч ночи), чем в группе контроля (36,07 и 35,84 соответственно, $p=0,027)$, а самое низкое значение БТ наблюдалось в 8.00 ч $(p<0,001)$. Таким образом, уже на фоне НГН и НТГ уровень БТ не соответствовал нормальным значениям, а в группе СД2 он был выше на протяжении всего дня ( $<<0,0001)$. Акрофаза гликемии натощак при РНУО была смещена во время бодрствования, а при СД2 все 24 ч ( $<<0,001)$.

ВЫВОдЫ: частые приемы пищи, поздний завтрак и ужин, нерациональное распределение калорийности в течение дня, преобладание в рационе углеводов- факторы, усугубляющие состояние инсулинорезистентности. Нарушение сна, с укорочением его продолжительности, смещением времени отхода ко сну и воздействием искусственного освещения в вечернее время, смещает циркадные ритмы сна и выработки мелатонина, что может провоцировать ухудшение гликемического контроля. 